Chapter to be published in Frontiers in Developmental Science: Social Cognition (Ed. Sommerville, J., Decety, J.). Psychology Press, Taylor and Francis Group

Buon Marine $^{1}$, Habib Marianne ${ }^{2}$ and Frey Darren ${ }^{1}$

\title{
Moral development: conflicts and compromises
}

${ }^{1}$ Laboratory for the Psychology of Child Development and Education (La PsyDE) - Paris

Descartes University, Sorbonne - Labo A. Binet, 46 rue Saint-Jacques, 75005 Paris, France

${ }^{2}$ Paragraph Laboratory (EA349) - Paris 8 University, 2 rue de la Liberté, 93526 Saint-Denis

Cedex 02, France 


\section{Moral development from an historical viewpoint}

\section{The development of morality from a rationalist perspective}

Moral codes, norms, values, and beliefs provide the framework for how individuals make decisions about how to treat one another and how to coexist in non-aggressive and communal ways. For a long time, morality has been the province of philosophers. For instance, according to Kant's rationalist view, the acceptance of moral norms is the rational output of processes of practical reasoning. Conversely, Hume's theory of moral sentiments suggests morality results from one's emotional and affective experiences. The first empirical research into the psychological bases of moral judgment and decision-making emerged in the mid-twentieth century. Drawing on the Kantian rationalist tradition, most early moral psychologists posited that morality is based on reasoning and develops through the maturation of children's cognitive functions as the child interacts socially (Kohlberg, 1969; Piaget, 1932; Turiel, 1998), though others like Bandura (1986) in the social-leaning theory of moral development emphasize the importance of adult reinforcement and imitation. In line with the rationalist perspective (Figure 1a), Piaget (1932), the pioneer in the study of moral development, investigated the development of children's moral competencies by probing their ability to justify their judgments about moral dilemmas. Using this method, Piaget described two stages of moral development. Before 7-8 years of age, children are at the first stage of morality: they strictly respect rules dictated by authorities such as adults. They consider these rules as given and accept that authorities have the right to reward those respecting the rules and to

punish those transgressing them. At this stage, children base their moral judgment on the 2 
consequences of an action without considering the intentions behind it. Children then reach the second stage of morality (autonomous morality) around the age of 11-12. At the second stage, children consider moral rules to be modifiable and based on social agreement. They also believe adults are sometimes unfair in their punishments. So at this stage, children do not solely base their moral judgments on the consequences of their actions, but also consider the agent.

Following Piaget's work, Kohlberg (1969) studied moral reasoning by presenting children with hypothetical moral dilemmas. In the most famous one, the Heinz dilemma, a husband has to decide if he should steal a drug to save his dying wife's life. Based on children's justifications of this type of dilemma, Kohlberg proposed that the development of moral reasoning has six identifiable stages grouped in three levels (pre-conventional, conventional, and post-conventional, table 1). In line with Piaget, Kohlberg described moral development as an invariant, universal, and hierarchical sequence of stages progressing as a function of socio-cognitive development. Moral development thus proceeds gradually from one stage to the next, in a predictable and ordered sequence.

While Piaget and Kohlberg's work has provided critical insights with respect to the development of morality, several empirical discoveries have led to a complete revision of their model, including their main rationalist assumptions.

\section{How did the Social Domain Theory jeopardize Piaget and Kohlberg's model of moral development?}


Piaget and Kohlberg's models of moral development were first challenged by Turiel and Nucci (1978) who proposed that young children's conception of social events varies with the type of issues involve. In particular, they proposed that from an early age, children are able to distinguish moral transgressions (violations of fairness, others' welfare, and rights) from conventional issues (i.e, authority-sanctioned or social conventions about how groups and institutions work). In line with this hypothesis, they observed that whereas moral events allow preschoolers to communicate about hurt and injury, transgressions of conventions trigger talks about the need to follow rules and matters of social order. Following this hypothesis, Smetana (1981) demonstrated that children as young as 2.5 years-old consider violations of moral transgressions as more serious than violations of social conventions: when two and a half year-olds are presented with scenarios depicting a child's moral transgression (e.g., stealing, pulling hair, hitting another child), they judge them as worse than flouting social conventions (e.g., going to school wearing pajamas, talking without raising his hand in class). Furthermore, they continue to evaluate the action as wrong even if the teacher did not see it (authority jurisdiction) or if it occurs at home, at school, or in another country (generalizability). They will also judge it as being wrong even if rules permit it. This series of findings, which demonstrates that young children distinguish moral transgressions from conventional transgressions, clearly contradicts Piaget and Kolberg's model of moral development since, according to them, preschoolers' moral judgments should strictly depend on the rules dictated by authorities. These subsequent findings lead to a very influential framework called the "social domain theory," according to which individuals' interpretations of the social world enable them to construct qualitatively distinct domains of social knowledge that undergo parallel 
developments from the start (Smetana, 2006; Turiel, 1998; Turiel \& Nucci, 1978;). In line with Piaget and Kohlberg's constructivist assumptions, these domains result from children's differentiated social interactions and experiences with both their parents and their peers. However, in contrast to Piaget and Kohlberg's views, the development of morality does not follow a stepwise progression from one stage to another but instead results from conflicts between legitimate, yet competing social, personal or moral concerns, and the ability to coordinate and evaluate multiple criteria to assess these situations (Smetana, 2006).

\section{The rediscovery of moral intuitions}

Piaget and Kolberg's major assumption has also recently been challenged by various disciplines within cognitive and social sciences suggesting that at least some of our moral competencies rely on socio-moral intuitions about how individuals should act toward one another. According to this view, individuals' responses to moral events are primarily intuitive, relying on rapid, automatic, and unconscious psychological processes (Haidt, 2001). This position was initially motivated by the phenomenon of moral dumbfounding — the fact that adults are not always able to justify some of their moral judgments (Haidt, 2001). If individuals are unable to offer convincing justifications in support of their judgments, it does not seem likely that their judgments were generated by a priori reasoning. Instead, according to Haidt, individuals use reasoning to justify their judgments in a post-hoc and biased way, generating moral judgments based on non-verbal and automatic social intuitions. Moral dumbfounding gave rise to several competing proposals regarding the very nature of individuals' intuitions about moral events. For instance, Haidt (2001) suggested the 
"social intuitionist model" where a moral event gives rise to emotions, which then determine our moral judgment of the event and/or the agent involved (Figure 1b).

According to Mikhail's moral grammar theory, human minds possess a complex and potentially domain-specific set of rules, concepts and principles that enable individuals to intuitively determine the moral status of an infinite variety of acts and omissions (Mikhail, 2007). However, by contrast, to Haidt (2001), Mikhail proposes that individuals' moral intuitions do not arise from their affective reactions to moral events but rest upon unconscious computations of the causal and intentional structure of agents' actions. Thus, even though moral intuitions may lead to affective reactions, affect is not critical for moral intuitions to occur (Figure 1c, Mikhail, 2007).

Given these frameworks, many empirical studies in cognitive science have investigated whether our moral judgments rest upon automatic processes and are critically associated with emotional processes (for a review of these studies, see Cushman, Young \& Greene, 2010). Substantiating the role of nonverbal and non-costly processes in adults' ability to generate moral judgments, several experiments have confirmed that people cannot always offer correct justifications for their moral judgment; similarly, others show that at least some forms of moral judgments remain unchanged under cognitive load. Evidence for the role of affect is largely neuroscientific, but a few behavioral studies of moral judgment using affective priming manipulations are also in line with this assumption. 


\section{Toward a compromise: dual process models of morality}

Even though empirical research investigating the processes underlying mature moral competences highlight the involvement of automatic and emotional processes in adults' morality, it has become increasingly clear that they do not solely determine individuals' moral judgments. Indeed, research indicates that moral judgments also involve many other mechanisms that could hardly operate at an intuitive level (e.g., Theory of mind -ToM-, abstract reasoning or cognitive control).

This led researchers to propose a more integrated view according to which moral judgment relies on the operation of distinct psychological systems, some of which rest upon intuitive/emotional processes while others rely on rational/controlled processes (Cushman et al., 2010). According to Greene (2009), emotional/intuitive systems tend to dominate people's judgments in situations of conflict, unless they are able to deploy important executive resources to evaluate more rational considerations (Greene, 2009; Figure 1d). According to another view, some situations can trigger a conflict between competing intuitive/automatic evaluations and require individuals to exert more effort thinking deliberately about moral beliefs to explicitly resolve the conflict (Figure 1e, Dupoux \& Jacob, 2007). Even though the precise cognitive architecture underlying adults' moral abilities remains to be established (e.g., Huebner, Dwyer \& Hauser, 2008), most scholars agree that moral judgments depend on both intuitive and controlled processes, and that adults' morality rests upon the ability to deal with and integrate conflicting moral and social considerations. It has also become increasingly clear that moral judgments likely involve a series of shared resources that are not 
solely dedicated to moral computations, nor do they uniquely determine individuals' moral judgment (Young \& Dungan, 2012).

From a developmental perspective, these recent advances in the understanding of the processes underlying adults' moral competencies have an important impact on the investigation of children's moral competences. Firstly, the phenomenon of moral dumbfounding clearly questions the relevance of studying children's justifications of their moral judgment in order to determine the development of moral competencies, since these may always be considered as biased post-hoc rationalizations of moral judgments. Secondly, evidence in favor of socio-moral intuitions in adults suggests that preverbal infants, whose experience, in addition to verbal, reasoning and cognitive skills are relatively limited, may be equipped with socio-moral intuitions. Thirdly, since adults' moral judgments also require the deployment of costly cognitive processes and deliberative reasoning, children must undergo important developmental changes, triggered by cognitive development and various socialization factors before reaching adult morality. Consequently, current investigations of development are divided into two main frameworks: On the one hand, developmental psychologists have used paradigms suitable for the analysis of preverbal infants' categorizations, expectations, and evaluations of moral events to demonstrate that prelinguistic infants are endowed with fairly sophisticated socio-moral competencies. On the other hand, developmental researchers focusing on the maturation of moral judgment across childhood and adolescence have revised and refined Piaget and Kohlberg's developmental trajectories and documented how children's moral abilities gradually increase under the influence of cognitive development, their environment, and socializing factors. 
In the following sections, we will describe some of the most important developmental findings about infants and children's abilities to treat (a)moral behaviors. In doing so, we will demonstrate that although prelinguistic infants and preschoolers are able to evaluate a wide range of moral actions, the generation of truly adult-like moral abilities emerges gradually during development, especially when children have to deal with events involving competing moral, social and personal considerations.

\section{Infant's early socio-moral competencies}

\section{Infants' categorization and evaluation of uncooperative and harmful agents}

The first study that investigated the existence of infants' social moral competencies explored whether infants were able to categorize different antisocial acts (hindering and harming) along the same dimensions. Premack and Premack (1997) presented 10-month-old infants with interactions between pairs of 2-D balls on a computer screen. In the habituation phase of the experiment, infants saw one ball performing either a negative action towards another ball (hitting or preventing the ball from achieving its goal - hindering) or a positive action (caressing or helping). Measures of the infants' looking times showed that infants who were habituated to a positive action (i.e, caressing or helping) looked longer at the event with the negative action (i.e, hitting), which does not occur for infants who were habituated to another negative action (i.e, hindering). Thus, it seems 10month-old infants are able to categorize actions along their positive or negative valence based on the low-level kinematic characteristics of the actions. Hamlin and collaborators (see Hamlin, 2013 for a review of their work) went a step further and demonstrated that 6- and 10-month-old infants 9 
are able to evaluate agents socially as a function of their performed actions. They presented infants with a ball (the Climber) attempting to climb a hill, which was alternately: i) pushed up the hill (helped) by a large yellow cube-shaped agent (the Helper); or ii) pushed down the hill (hindered) by a large green triangle-shaped agent (the Hinderer). They assessed infants' preferences about the Helper and Hinderer as a result of viewing their previous antisocial and prosocial actions by giving infants the opportunity to grasp the Hinderer or the Helper characters. Most of both 6- and 10month-olds' infants chose to reach the Helper, suggesting that they considered the Helper to be a more positive agent to interact with and/or the Hinderer to be a negative agent to interact with. When infants had to choose between a Helper and a Neutral agent (i.e, an agent who did not interact with the Climber and follows a path identical to that of a helper), or between a Neutral agent and a Hinderer, infants preferred interacting with the Helper and the Neutral agent, respectively, demonstrating that infants' social preferences were guided by both a positive evaluation of (and a tendency to interact with) the Helper and a negative evaluation of (and a tendency to avoid) the Hinderer. This social preference toward an agent who helped over an agent who hindered one of his associates seems to be robust, as several studies replicated this pattern of results using other scenarios (e.g., agents who try to open a box or retrieve a dropped ball) and slightly different ages (5- and 8-month-olds).

In a subsequent study, preverbal 8 month-old infants were shown to prefer agents who hindered the hindering agent over agents who helped hinderers. According to a lean interpretation of this latter result, infants' behavioral patterns mainly rely on a simple-matching preference: infants prefer to interact with the character who hindered a hinderer because the negative valence of this 10 
character's act matches the negative valence of the act the hinderer was involved in before (Scarf, Imuta, Colombo, \& Hayne, 2012). Alternatively, this result may indicate that infants detect moral retribution (i.e, the tendency to reward those who behave prosocially and to punish those who do not) and preferred individuals who acted consistently with this principle (Hamlin, 2013). This mechanism is thought to be critical for the evolution of cooperation and morality since it enforces cooperative behavior by deterring potential free riders. In line with this interpretation, using the same type of stimuli, Hamlin and collaborators also demonstrated that 20 month-old toddlers were more likely to give an attractive treat to the helper and to take one from the hinderer (see also Kenward \& Dahl, 2011 for similar results with preschoolers), suggesting that human are endowed with such a retribution mechanism from an early age.

In line with findings suggesting that 10-month-old infants treat comforting/harming actions along the same dimensions as helping/hindering actions, recent evidence also indicates that 10- montholds' social preferences are sensitive to actions involving harm or comfort (Buon et al., 2014). In this experiment, participants were presented with movie clips involving i) a human antisocial agent pushing down another agent who then cried and comforted an inanimate object, and ii) a human pro-social agent who comforted another agent and pushed the inanimate object. 10-month-olds more often chose a toy proposed by the prosocial rather than by the antisocial agent. Importantly, the overall amount of aggressive/threatening cues and comforting/smiling cues displayed by both the prosocial and the antisocial agents were constant, as were the emotional expressions of the human subject. Thus, infants and toddlers did not only base their evaluations on the physical actions performed by the agent or the basic emotional cues depicted in the movie clips. It remains to be 11 
seen whether infants responded based on a positive evaluation of the prosocial and/or negative evaluation of antisocial agent. However, the authors reported that 29 month-old toddlers' verbal appraisals of the antisocial and prosocial agents were respectively negative and neutral, suggesting that participants were mostly sensitive to the harmful impact of the antisocial agent and not to the positive impact of the prosocial agent's action.

\section{Infants' sensitivity to fairness in other's behavior}

With respect to infants' sensitivity to issues of fairness, preverbal infants have been shown to expect individuals to be fair in their allocations of resources. Schmidt and Sommerville (2011) showed that toddlers aged 15 months expect resources to be shared equally. Interestingly, infants' expectations were systematically related to their altruistic behavior (i.e, sharing their preferred toys). In another study, 18 month-old infants were presented with a lion distributing shares of attractive toys (multicolored-disks) equally between two recipients and a bear distributing toys unequally. Eighteen month-old infants (but not 10 month-old) were surprised when a third party observer approached the lion, suggesting that infants expect individuals to approach the fair donor rather than the unfair one (Geraci \& Surian, 2011). Infants were also more likely to pick the agent who distributed the resources equally. Importantly, their preferential grasping of the agent disappeared when the recipients were replaced with inanimate objects, suggesting that infants' social preferences were not simply based upon the experimenter's physical movements. More recently, Meristo and Surian (2013) familiarized 10-month-old infants with one 'fair donor' distributing resources equally and another donor who gave all his resources to only one recipient 
while a third agent was witnessing the interaction or not. During the test phase, the third agent took resources away either from the fair donor or the unfair donor. Infants were surprised when the antisocial action was directed toward the fair donor but they did so only when the third agent could witness the donor's actions during the familiarization phase, suggesting that infants' expectancies are consistent with the principle of moral retribution described above.

\section{Summary of infants' early social competences}

The evidence described above suggests that preverbal infants are able to evaluate a wide range of moral events along the same dimensions as those used by adults. Given infants' limited verbal and executive skills, this suggests that -- in line with research on adults that demonstrates that at least some of their moral judgments rely on intuitive processes -- infants do have socio-moral intuitions about moral events. No study has yet explored infants' early socio-moral competencies in relation with their social environment and relatives' behaviors, which prevents us from completely ruling out the hypothesis that infants may have learned moral principles and built expectations from their observation of others' actions and/or emotional responses to moral events.

However, the fact that 10 month-old infants have (arguably) little experience with moral interactions has led several researchers to propose that human morality has an innate basis and is at least partially evolutionary rooted (Hamlin, 2013).

According to Hamlin, such a 'moral core' would have evolved to sustain collective actions and cooperation that lead to greater mutual gain but sometimes require personal costs. These early 
socio-moral competencies rest upon human's abilities to feel concern towards (and help) others, which is probably rooted in empathic processes whose rudiments are present from birth (Davidov, Zahn-Waxler, Roth-Hanania \& Knafo, 2013) and also in our primate relatives (Tomasello \& Vaish, 2013).

While very attractive, this proposition should be treated with caution. First, investigations of infants' socio-moral competencies are just recently beginning and additional studies are required to: i) understand what morally relevant (or irrelevant) properties infants are responsive to, ii) fully rule out all possible low level interpretations of the results described above, and iii) support the rich interpretation that babies possess the core of what we would describe as adults' moral sense (Haith, 1998). Second, morality includes evaluations of many types of events and whether it serves a unique adaptive function as proposed by Hamlin (2013) remains an open question. Indeed, some suggest that morality relies on distinct domains (e.g., fairness, harm, cooperation and so on), each one depending on functionally specialized mechanisms (see Dungan \& Young, 2015 for a critical review). Relatedly, the mechanisms by which infants form the expectations and evaluations described above remain unestablished. If, as proposed by Hamlin et al., (2013), infants' early competencies are intrinsically motivated by infants' concerns for others, then one should observe a connection between the two, which, to the best of our knowledge, has not been investigated yet.

Even though the ultimate and proximate mechanisms by which infants are able to form such sociomoral evaluations remains to be established, it should be noted that the potential existence of innate moral core(s) does not necessarily preclude socio-cultural and cognitive factors from strongly 
influencing children's moral development. Instead, according to some 'nativist' theories of moral cognition, infants have intuitions that establish the boundaries for a mature moral sense. These intuitions are then modulated by social and cultural input, leading to the adjustment of these intuitive mechanisms as well as the range of content to which they are responsive (Haidt \& Joseph, 2007). In addition, as suggested earlier, moral development may also involve an increasingly complex integration of various moral and non-moral computations, which may be highly useful for processing everyday moral questions, which can be much more complicated than situations used in experiments to probe infants' socio-moral abilities and likely require the development of high order cognitive capacities.

We will now turn to studies that have explored preschoolers, children and adolescents' moral competencies. In this section, we will show that while preschoolers moral competencies are - in line with infants' early socio-evaluative abilities - fairly sophisticated, childhood and adolescence are marked by important developmental milestones that are likely to rely on a complex interaction between socialization and environmental and cognitive dimensions.

\section{Moral development from preschool to adolescence}

\section{Preschoolers are moral judges, actors and norm enforcers}

Infants' evaluative abilities reviewed above are mostly considered 'pre-moral' i.e, precursors of moral thoughts. We purposely categorize these evaluative abilities as "socio-moral" since they concern interactions that are typically perceived by adults as '(a)moral'. However, infants' studies 
of the above sort can only reveal infants' social expectations or preferences and, given these results, cannot substantiate that infants have moral thoughts. Ideally, future developmental work should explore longitudinally whether preverbal infants' socio-moral expectations and evaluations predict young preschoolers' behaviors in tasks probing their moral competencies (see Yamaguchi, Kuhlmeier, Wynn \& VanMarle, 2009 for similar work done with ToM competencies). In the meantime, it is worthwhile to consider whether preschoolers more sophisticated verbal judgments and moral behaviors extend the same social-moral competencies found in infants.

As already reported, results from social domain theory suggest that children as young as 2.5 years old distinguish moral from conventional transgressions on several criteria, including generalizability and independence of authority or punishment mandates. Social domain theory classifies moral transgressions as violations of prescriptions about fairness, other's welfare, and rights, which is consistent with the existence of early intuitions about harm and fairness that we documented before (Smetana, 2006). For Turiel (2006), the moral-conventional distinction results from the child's ability to empathize (i.e, the capacity to share or become affectively aroused by others' emotions) with the victim in moral transgressions but not in conventional transgressions. That is, when children see moral transgression, they learn a prescriptive norm against it because they imagine the pain or distress that such an action would cause him or herself. This is in line with Hamlin's perspective, which stresses the importance of care-based emotions for early moral competencies. Others findings argue in favor of the importance of affective processes in the development of moral competences : for instance, it has been shown that moral transgressions were evaluated as affectively negative by preschoolers, while conventional transgressions are viewed as 16 
affectively neutral (Arsenio, 1988). Interestingly, however, evidence indicates that preschoolers' negative evaluation of moral transgressions does not necessarily rely on an automatic reaction to distress cues since actions provoking an unreasonable and unjustified distress have been shown to not elicit condemnation by preschoolers (Leslie, Mallon \& DiCorcia, 2006). This result suggests that preschoolers are able to represent the intrinsic consequences of a moral transgression, probably based on a more complex mechanism than simple affective sharing. A good candidate is affective perspective taking, which is imagining or inferring what the other person is feeling based on various non-emotional and situational cues and by putting oneself in the other's place (Eisenberg, Shea, Carlo, \& Knight, 1991). Preschoolers are also able to consider as wrong, and deserving of punishment, psychological harms such as acts that cause embarrassment (Helwig, Zelazo \& Wilson, 2001), or acts of social exclusion (Theimer, Killen \& Stangor, 2001), that imply more subtle, though not less important, negative outcomes compared to physical harm.

Regarding the sensitivity to equal distributions of resources, preschoolers apply this principle in their sharing behaviors, at least when their self-interest is not at stake in the distribution. For example, Olson and Spelke (2008) presented 3.5 year-old preschoolers with five dolls, one identified as the protagonist while the four others were identified as the protagonist's siblings, friends, or strangers. When the children were asked to help the protagonist distribute four attractive items, the items were distributed equally among the others' dolls regardless of their relationship with the protagonist, demonstrating that children do apply the principle of equity in their distributing behaviors. This preference to distribute resources equally (in third party sharing tasks) has been shown to be so strong that it could even hide preschoolers' capacity to make nuanced 17 
evaluations. For instance, Baumard, Mascaro and Chevalier (2012) explored whether young children are able to take merit into account when distributing resources. To this aim, three and four year-old preschoolers were asked to distribute three identical cookies between two boys, one who greatly contributed to the baking of the cookies and another whose contribution was small. Preschoolers' spontaneous distributions of cookies were mostly egalitarian (one cookie for each), and the children favored the boy who contributed more only when the experimenter requested them to distribute the last cookie. Similarly, young preschoolers are able to distinguish between helpers and hinderers in their distribution of goods only when the participant had a small even numbers of biscuits to distribute but not when the distributions were more plentiful (Kenward \& Dahl, 2011).

Beyond being efficient moral judges and actors, preschoolers are also active norm enforcers, which is congruent with infants and toddlers' presupposed sensitivity to the principle of moral retribution described above. Preschoolers reciprocate more with puppets who behave prosocially than others (Kenward \& Dahl, 2011, Olson \& Spelke, 2008), but they also intervene actively when witnessing puppets' transgressions (for a review see Jensen, Vaish, \& Schmidt, 2014). For instance, when faced with someone committing a moral transgression (i.e, a puppet destroying another puppet's property) or a conventional one (i.e, a puppet playing a game in a deviant way), young children protest, tattle and try to alter the transgressor's behavior by teaching it the right thing to do. Importantly, evidence also indicates that young children do not reinforce conventional and moral norms equally. In particular, three-year-old children were presented with a puppet breaking a conventional transgression and one engaged in a moral transgression. Puppets either belonged to the child's group (in-group member) or not (outgroup member). While young participants actively 18 
protested when puppets committed moral transgressions regardless of their group membership, they did so for the conventional transgression toward the in-group member only. This suggests that preschoolers understand that moral norms need to be applied universally to members of all social categories equally, while conventions only need to be applied within a given social group.

Together, the evidence described above indicates that young preschoolers judge, apply and reinforce a wide range of moral principles, which is consistent with (and extends) infants' early socio-moral competencies. Despite these sophisticated moral competencies, preschoolers' moral evaluations and behaviors do not absolutely resemble those of adults, especially when the situation triggers competing interests. To illustrate, we will now describe how long it takes for children i) to fully incorporate information about agents' intentions in their moral evaluation, and ii) to favor fair distributions of resources even when it is costly to do so.

\section{The gradual emergence of intention-based moral judgment}

A critical component guiding adults' moral judgments about moral transgressions is intention (i.e, whether an agent wanted to cause harm or whether he/she inflicted harm by accident). Since sometimes prosocial and antisocial actions are physically identical (e.g., you may want to push someone to hurt her or to keep her from being crushed by a car), intention is indeed a crucial component of social and moral evaluation. Even though adults' moral judgments are sensitive to 19 
the negative impact of an agent's action, intention actually predominates adults' moral evaluations of the agent's character as well as judgments about the wrongfulness of his actions and the punishment he deserves (Piaget, 1932). Indeed, adults tend to evaluate individuals that accidentally caused harm more leniently than individuals that wanted to cause harm but failed to do so.

When considering children's ability to integrate whether an individual wanted to cause harm or not, developmental research indicates that it takes an especially long time for children to be able to prioritize information about agents' mental states in their moral judgments as adults do. Indeed, even though some studies showed that young children are able to judge that an agent causing harm intentionally is naughtier than an agent causing harm accidentally (e.g., Cushman, Sheketoff, Wharton, \& Carey, 2013, see also Hamlin, 2013 for recent evidence with infants), preschoolers' moral judgments do not completely resemble those of adults. It is not until the age of 7 or 8 that children are robustly able to prioritize information about intentions in their moral judgments. Between 3 and 8 years old, most studies still show a decrease in the use of consequences of the action perceived and an increase in the use of intentions to determine whether an action is wrong, and whether an agent is naughty or should be punished (e.g., Cushman et al., 2013; Nobes, Panagiotaki, \& Pawson, 2009). This late emergence of the ability to fully incorporate intentions into moral judgments may be quite surprising since young children and even preverbal infants have been reported to be sensitive to a wide range of mental states, including agents' desires, intentions, beliefs, and false beliefs (for review see Baillargeon et al., 2015). 
With respect to this issue, children find it especially difficult to generate intent-based moral judgments when the situation perceived involves conflicting evaluations (i.e, case of accidental harm in which the agent causes harm but did not mean to; Cushman et al., 2013). In addition, when faced with such situations, children are especially bad at integrating intentions when the intentions underlying the agents' action are implicit while the outcomes of the action are highly salient (Baird \& Astington, 2004). Thus, what may be especially complicated for young children is to override the negative reactions arising from the perception of the agents' harmful causal role in order to consider more abstract and less salient components of the scenario. In line with this hypothesis, research on adult populations has demonstrated that moral sensitivity to an agent's harmful causal role relies on both automatic/intuitive processes (Buon, Jacob, Loissel, \& Dupoux, 2013) and intact empathic processing (Young, Koenigs, Kruepke \& Newman, 2012), while integrating the agents' intentions rests upon more costly and probably non-emotional cognitive processes. It has been proposed that robust ToM abilities (the ability to explicitly represent and use agents' mental states to explain other people's behaviors in a flexible way, see Apperly \& Butterfill, 2009) and inhibitory control resources are critical for individuals to completely override the emotional intuition triggered by the harm caused (Buon et al., 2013).

In keeping with these hypotheses, several studies report that children's incorporation of agents' intentions in their moral judgments were significantly associated with their ability to pass the False Belief Task (FBT; Killen et al., 2011; Baird \& Astington, 2004). For instance, children's capacities to pass the FBT are positively correlated with their abilities to distinguish two individuals based on their intention to cause harm, suggesting that full-fledged ToM competencies are critical to 21 
integrating the mental state of transgressors into moral judgements (Baird and Astington, 2004). Using functional magnetic resonance imaging to assess moral processing in a sample spanning from 4 to 37 year-olds, interesting neurodevelopmental changes have been evidenced in the structures typically involved in processing affectively salient stimuli (i.e, amygdala and insula), with the level of activation in these brain areas decreasing with age. Conversely, activity in the region thought to be involved in resolving conflict, decision-making, and evaluation (i.e, dorsolateral and median prefrontal cortex) increased with age. Even though these data are correlational, they suggest that processing moral situations is more dependent upon basic affective responses in younger participants than in older participants, while older children are more prone to adopt an evaluative stance enabling them to deal with the conflicting evaluations (Decety, Michalska, \& Kinzler, 2011)

While the multiple factors responsible for this important developmental milestone and the potential interactions between them remain highly debated, the findings described above show that Piaget was not completely wrong in claiming that the development of moral maturity depends on the development of children's cognitive abilities. Children seem to become increasingly able to deal with competing moral considerations thanks to the development of their explicit ToM capacities and their ability to evaluate situations using non-affective routes. By turning to the development of inequity aversion, we will now show that this increasing ability to deal with complex moral events and competing considerations across development can also extend to issues of fairness and sharing behaviors. 


\section{Sharing and altruistic behaviors from preschool to mid-childhood}

Although infants and preschoolers' sensitivities to fairness and equal distributions of resources may be fairly sophisticated, the findings we have reported so far only use tasks in which infants and preschoolers could not benefit from the distribution. Research probing adults' concerns for fair distributions of resources typically shows that adults do not only evaluate unfair distributions of resources negatively, but also engage in sharing behaviors even if it minimizes their own benefits (for a review, see Camerer and Thaler, 1995). For instance, in the Dictator game, the participant decides how to distribute a fixed amount of money between himself and another participant. In this game, participants have to decide whether to share a fixed amount of money between themselves and a potential recipient. Adult participants typically give money to potential recipients even if they cannot know the identity of each other and do not receive any reward for their altruistic sharing. This result is in sharp contrast to most classical economic models that anticipate individuals will propose the smallest possible amount in such a scenario. The Ultimatum game demonstrates that adults spontaneously engage in costly punishment. In this game, an individual makes a proposal on how to distribute a fixed amount of money with a second individual. It differs from the dictator game as the recipient has the opportunity to either accept (and earn the amount proposed) or reject the amount proposed (and earn nothing). Here again, although classic economic models suggest receivers should accept all offers, adults typically reject unfair offers (below 30\%). These behaviors confirm that individuals are much more socially oriented and altruistic, and much less selfish than previously thought. This ability to override selfish motives, however, seems to follow a protracted development. 
Indeed, when we turn to research exploring children's responses to sharing situations in which they are personally involved, results typically show that preschoolers evaluate and engage in resource allocations from a selfish point-of-view. For example, McCrink, Bloom \& Santos (2010) presented 4 and 5 year olds and adults with a 'giving game' in which two puppets with different numbers of chips gave some portion of these to the children. The absolute amount and proportion of chips given to the child were manipulated, with children being asked after each manipulation, "Which puppet do you think is nicer?". Although adults focused only on the proportion given, the judgments of 4-year-olds were exclusively focused on the absolute number of chips they received. For example, if a 'poor' doll (which only had 4 chips) gives 2 chips and a rich one (with 12 chips) gives 4 chips, adults considered the poor doll to be the nicest though 4-year-olds responded in the opposite way. Similarly, when asked to distribute sweets between themselves and another anonymous child, children at age 3-4 showed little willingness to share resources, especially if sharing is costly (Fehr, Bernhard \& Rockenbach, 2008).

Such a 'selfish' pattern of responding has been observed in several distinct experimental settings and in preschoolers from different cultures, from small rural communities to large urban settings (e.g., Rochat et al., 2009). Relatedly, while we already described that preschoolers were able to engage in seemingly non-costly norm enforcement behaviors, at 5 years of age children do not engage in costly punishment (McAuliffe, Jordan \& Warneken, 2015), confirming that preschoolers are not willing to reinforce norms if it involves sacrificing one's own resources. 
A closer look at the trajectory underlying the development of sharing behavior across childhood reveals a slight decrease in selfish considerations around the age of 4 or 5 , but the clear preference for egalitarian distributions does not occur before the age of 8 years and continues to strongly guide children's decisions until late childhood (i.e, 11 years-old, see for instance Almås, Cappelen, Sørensen, \& Tungodden, 2010). Evidence also shows that by the age of 6, children start to be able to engage in costly punishment to prevent unequal distributions from occurring (McAuliffe et al., 2015). Interestingly, this bias for equal distributions is so strong that by mid-childhood, children's positive intentions, like generosity, motivate them to assume costly payments to prevent unequal distributions (e.g., generosity, McAuliffe et al., 2015). In summary, though the sensitivity to equal sharing of resources appears at an early age, children's ability to weigh the desires or the welfare of others while suspending their own immediate gratification develops gradually from preschool age to late childhood.

The factors motivating this important developmental change remain unclear, but interactions among socialization and environmental and cognitive dimensions are likely to be at play in the emergence of children's inequity aversions in first party tasks. Several authors have proposed that the development of ToM capacities may be critical for several reasons: ToM would help children to consider the perspective of the giver or increase children's sensitivity to the opinion of others (i.e, reputation, Ferh et al., 2008), by allowing them to understand that their own actions affect what others believe about them. The development of executive resources and top-down controlled processes may also be critical in helping children to suspend or inhibit their own desire for immediate gratification (Rochat et al., 2009). In favor of this conclusion, one recent study using a 25 
variant of the ultimatum game showed that adults were more likely to accept unfair offers when asked to respond the offers based on their 'gut feelings,' suggesting that selfish motives may be more intuitive than moral motives (inequity aversion) when both are conflicting (Hochman, Ayal \& Ariely, 2015 but see Rand, Greene \& Nowak, 2012). In another developmental study using an electroencephalogram, five year-old children's sharing behaviors correlated positively with LPP (late positive potential) responses during watching helping (vs. harmful) situations (Cowell \& Decety, 2015). LLP responses are thought to reflect cognitive reappraisal and top-down cognitive control, which demonstrates that children's sharing behaviors probably rely on costly reappraisals of emotionally-charged moral situations.

There is also evidence in favor of the role of environmental and socialization factors in the development of the ability to share resources altruistically when self-interests are at play. Notably, several studies found that children's selfish behavior depends on some environmental factors such as whether a child grew up as a single child or is the youngest child in a family (Fehr et al., 2008) or whether the culture in which the child grows up promotes collective or individualistic values (Rochat et al., 2009). More recently, it has been demonstrated that the threat of second or third party punishment led preschoolers to behave more generously (Lergetporer et al., 2014). Even though the precise impact of those factors on children's cognitive and moral abilities remains to be established, environmental and societal influences seem to impact children's moral development. 


\section{And what about adolescents?}

By middle childhood, children thus reach an important milestone in the development of moral competencies and are able to override their selfish interests to behave fairly and in altruistic ways, but their moral development continues to mature. Adolescence is a period characterized by the ongoing development of cognitive dimensions strongly related to the development of moral competencies such as affective and cognitive perspective taking and executive control (Blakemore \& Robbins, 2012). Compared to childhood, adolescence is also a developmental period during which increasing time is spent with peers. Consequently, peers and social context have an increasing influence on adolescent behavior and decision making (Steinberg \& Morris, 2001). This crucial transition seems to have both positive and negative impacts on teenagers' social decision making and moral behaviors. On the positive side, adolescence is characterized by an increased ability to take into account their partner's individual characteristics and social contexts in their sharing and altruistic behaviors, which allows them to provide more nuanced and flexible moral behaviors than the strictly egalitarian pattern characterizing 7 to 11 year-old children (e.g., Almås, Cappelen, Sørensen, \& Tungodden, 2010; Van den Bos, et al., 2010). For example, Almas et al., (2010) showed that by increasing age, adolescents' sharing behaviors became more sensitive to their partner's effort and efficiency at collecting resources, leading to a dramatic drop in strict egalitarian distributions that predominate 11 year-old's behaviors. Similarly, adolescents are much more likely to incorporate their partners' social experiences (e.g., whether their partner has been previously victimized or victimizer, Will, Crone, van der Bos \& Güroglu, 2013) over a strict egalitarian distribution, a pattern that seems to especially characterize adolescents who scored high 
on a perspective-taking task (Fett et al., 2014). On the negative side, it may lead to greater partiality (e.g., in-group favoritism) and less forgiveness in situations where peer evaluations and acceptance are at stake. Indeed, several studies showed that parochialism actually increases during adolescence (Fehr, Glätzle-Rützler \& Sutter, 2013) and that adolescents can be more severe than children and adults in punishing individuals who previously engaged in acts of social exclusions (Will et al., 2013).

While studies exploring the influence of peers and social contexts on adolescents' cognitive appraisal of social situations and moral decisions are still emerging, morality during adolescence does not necessarily follow a linear development from childhood to adulthood, and from selfish evaluations to impartial moral appraisals and decisions. Thus, one interesting research agenda is to thoroughly characterize how social variables positively and negatively impact adolescents' moral decision making, while interacting with adolescents' ongoing cognitive development.

\section{Conclusions}

Since Piaget and Kohlberg, developmental psychologists have documented how children acquire and develop moral abilities. Although early research described the development of morality as being the result of a gradual construction of the moral sense as the child interacts with his environment, the influence of theoretical and empirical work on the intuitive basis of adults' moral competencies has launched a fruitful area of research that demonstrates that infants' socio-moral evaluations are sensitive to basic moral principles involving fairness and the welfare of others. By suggesting that at least some aspects of human morality are innate and present in our closest 
relatives, these discoveries generate a number of questions regarding the very nature and functions of those early moral competencies: what are the mechanisms guiding infants' early evaluations? Do all socio-moral intuitions rely on the same proximal and functional mechanisms? Are nonhuman primates endowed with such pre-moral intuitions?

In addition, while we have illustrated that preschoolers demonstrate fairly sophisticated moral competencies, being active moral judges, actors, and norm-enforcers, it remains to be established whether preschoolers' explicit judgments and moral behaviors rely on the same intuitive evaluative mechanisms that are supposed to guide infants' evaluations. While preschoolers' responses have long been considered to be the 'default mode' of research on human morality, they certainly have much more experience and cognitive skills available to apprehend moral interactions and social feedback than prelinguistic infants. Comparing infants, toddlers and preschoolers in future work is thus critical to clarify the nature of the evaluative mechanisms underlying the measures used in infants' studies and to characterize the developmental gaps and continuities between infants' social preferences and older children's explicit moral judgments.

Furthermore, we have illustrated how long it can take for children to prioritize principles of fairness, justice, or others' welfare over non-moral but potentially equally intuitive and hardwired tendencies (e.g., principle of fairness against self-interests), or to weigh competing moral considerations against each other (e.g., causal analysis against intentional analysis in case of accidental harm). This supports the position that moral development does not only rest upon intuitive mechanisms but also relies on the ability to deal with and integrate conflicting moral and non-moral considerations (Killen \& Smetana 2008), thanks to a complex interaction between 29 
socialization, environmental and cognitive dimensions. However, it should be noted that the impact of these different socio-cognitive variables on children's moral development remains unclear and is in need of additional exploration. Furthermore, the moral and social conflicts a child learns to deal with are multiple and varied, extending far beyond the cases of accidental harm and second party sharing tasks that we reported above. Care-based morality ('You shall not harm'), for instance, sometimes conflicts with a tendency to respond to moral provocations ("He attacked me!") for intuitive protective reasons. It may also conflict with our hardwired tendencies to be biased toward members of groups with which we identify and may result in distinct concerns and treatments for in-group and out-group members (Decety \& Cowell, 2014).

Researchers now face the challenge of clarifying the specific developmental features of the distinct systems governing humans' personal, social and moral concerns, as well as the processes of integration and competition among them (Cushman et al., 2010, Killen \& Smetana, 2008). They must also more clearly establish how the early emerging moral core combines with experience and other developmental mechanisms to create a culturally specific, adult moral sense. In order to address these fascinating questions, scientists will necessarily have to integrate empirical findings on moral judgment and behavior across developmental and neuroscientific perspectives, incorporating and contrasting findings from the entire range of ages, from infants to adults. Such an interdisciplinary perspective may help us clarify a number of the moral developmental controversies presented above and provide a fuller account of what underlies the emergence of the human moral sense. 


\section{References}

Almås, I., Cappelen, A. W., Sørensen, E. Ø., \& Tungodden, B. (2010). Fairness and the development of inequality acceptance. Science, 328(5982), 1176-1178. doi : $10.1126 /$ science. 1187300

Apperly, I. a \& Butterfill, S. (2009). Do humans have two systems to track beliefs and belief-like states? Psychological review, 116(4), pp.953-70. doi : 10.1037/a0016923

Baird, J. \& Astington, J.W., (2004). The role of mental state understanding in the development of moral cognition and moral action. New directions for child and adolescent development, 2004(103), 37-49. doi : 10.1002/cd.96

Baillargeon, R., Scott, R. M., He, Z., Sloane, S., Setoh, P., Jin, K., Bian, L. (2015). Psychological and sociomoral reasoning in infancy. In M. P. Mikulincer \& R. Shaver (Eds.), APA handbook of personality and social psychology (pp. 79-150). Washington: American Psychological Association.

Bandura, A. (1986). Social foundations of thought and action: A social cognitive theory. Englewood Cliffs, NJ: Prentice- Hall, Inc.

Blakemore, S.-J., \& Robbins, T. W. (2012). Decision-making in the adolescent brain. Nature Neuroscience, 15(9), 1184-91. doi:10.1038/nn.3177

Baumard, N., Mascaro, O., \& Chevallier, C. (2012). Preschoolers are able to take merit into account when distributing goods. Developmental Psychology, doi:10.1037/a0026598

Buon, M., Jacob, P., Loissel, E., \& Dupoux, E. (2013). A non-mentalistic cause-based heuristic in human social evaluations. Cognition, 126(2), 149-155. doi:10.1016/j.cognition.2012.09.006.

Buon, M., Jacob, P., Margules, S., Brunet, I., Dutat, M., Cabrol, D., \& Dupoux, E. (2014). Friend or foe? Early social evaluation of human interactions. PloS One, 9(2), e88612. doi:10.1371/journal.pone. 0088612

Camerer, C., and Thaler,R.H. (1995). Ultimatums, dictators and manners. The Journal of Economic Perspectives, 9(2), 209-219. doi:10.1257/jep.9.2.209 
Cowell, J. M., \& Decety, J. (2015). The Neuroscience of Implicit Moral Evaluation and Its Relation to Generosity in Early Childhood, Current Biology. 25 (1), 1-5. doi:10.1016/j.cub.2014.11.002

Cushman, F., Sheketoff, R., Wharton, S., \& Carey, S., (2013). The development of intent-based moral judgment, Cognition, 127(1), 6-21. doi:10.1016/j.cognition.2012.11.008

Cushman, F., Young, L., \& Greene, J. D. (2010). Our multi-system moral psychology: Towards a consensus view. In J. Doris (Ed.), The Moral Psychology Handbook (47-71) Oxford: Oxford University Press.

Davidov, M., Zahn-Waxler, C., Roth-Hanania, R. and Knafo, A. (2013). Concern for Others in the First Year of Life: Theory, Evidence, and Avenues for Research, Child Development Perspectives, 7: 126-131. doi: 10.1111/cdep.12028

Decety, J., \& Cowell, J. M. (2014). The complex relation between morality and empathy. Trends in Cognitive Sciences, 18(7), 337-9. doi:10.1016/j.tics.2014.04.008

Decety, J., Michalska, K.J. \& Kinzler, K.D., (2011). The Contribution of Emotion and Cognition to Moral Sensitivity: A Neurodevelopmental Study. Cerebral cortex, 22(1), 209-20. doi: 10.1093/cercor/bhr111.

Dungan, J. and Young, L. (2015). Understanding the Adaptive Functions of Morality from a Cognitive Psychological Perspective. In R.A. Scott, S. M. Kosslyn (eds.), Emerging Trends in the Social and Behavioral Sciences: An Interdisciplinary, Searchable, and Linkable Resource. John Wiley \& Sons (Wiley Online Library). doi: 10.1002/9781118900772.etrds0376.

Dupoux, E., \& Jacob, P. (2007). Universal moral grammar: a critical appraisal. Trends in Cognitive Sciences, 11(9), 373-8. doi:10.1016/j.tics.2007.07.001

Eisenberg, N., Shea, C. L., Carlo, G., \& Knight, G. P. (1991). Empathy-Related Responding and Cognition: A "Chicken and the Egg" Dilemma. In Handbook of Moral Behavior and Development (Vol. 2, pp. 63-88). Lawrence Erlbaum Associates.

Fehr, E., Bernhard, H. \& Rockenbach, B., (2008). Egalitarianism in young children. Nature, 454(7208), 1079-1083. doi: 10.1038/nature07155.

Fehr, E., Glätzle-Rützler, D., \& Sutter, M. (2013). The development of egalitarianism, altruism, spite and parochialism in childhood and adolescence.European Economic Review, 64, 369383. 
Fett, A.-K. J., Shergill, S. S., Gromann, P. M., Dumontheil, I., Blakemore, S.-J., Yakub, F., \& Krabbendam, L. (2014). Trust and social reciprocity in adolescence-A matter of perspectivetaking. Journal of Adolescence, 37(2), 175-184. Doi : 10.1016/j.adolescence.2013.11.011

Geraci, A. \& Surian, L., (2011). The developmental roots of fairness : infants ' reactions to equal and unequal distributions of resources. Developmental science, 14(5), 1012-20. doi : 10.1111/j.1467-7687.2011.01048.x

Greene, J.D., (2009). Dual-process morality and the personal/impersonal distinction: A reply to McGuire, Langdon, Coltheart, and Mackenzie. Journal of Experimental Social Psychology, 45(3), 1-4. doi : 10.1016/j.jesp.2009.01.003

Haidt, J., (2001). The emotional dog and its rational tail: a social intuitionist approach to moral judgment. Psychological review, 108(4), pp.814-834. doi : 1037//0033-295X.

Haidt, J., \& Joseph, C. (2007). The moral mind: How 5 sets of innate moral intuitions guide the development of many culture-specific virtues, and perhaps even modules. In P. Carruthers, S. Laurence, and S. Stich (Eds.) The Innate Mind, Vol. 3.

Haith, M. M. (1998). Who put the cog in infant cognition? Is rich interpretation too costly? Infant Behavior and Development, 21(2), 167-179. doi:10.1016/S0163-6383(98)90001-7

Hamlin, J.K., (2013). Moral Judgment and Action in Preverbal Infants and Toddlers: Evidence for an Innate Moral Core. Current Directions in Psychological Science, 22(3), 186-193. doi: 10.1177/0963721412470687.

Helwig, C. C., Zelazo, P. D., \& Wilson, M. (2001). Children's Judgments of Psychological Harm in Normal and Noncanonical Situations. Child Development, 72(1), 66-81. doi:10.1111/14678624.00266

Hochman, G., Ayal, S., and Ariely, D. (2015). Fairness requires deliberation: the primacy of economic over social considerations. Frontiers in Psychology. 6(747). doi: 10.3389/fpsyg.2015.00747

Huebner, B., Dwyer, S., \& Hauser, M. (2008). The role of emotion in moral psychology. Trends in Cognitive Sciences, 13(1) , 1-6. doi:10.1016/j.tics.2008.09.006

Jensen, K., Vaish, A., \& Schmidt, M. F. H. (2014). The emergence of human prosociality: aligning with others through feelings, concerns, and norms. Frontiers in Psychology, 5(822), 1-16. doi:10.3389/fpsyg.2014.00822 
Kenward, B., \& Dahl, M. (2011). Preschoolers distribute scarce resources according to the moral valence of recipients' previous actions. Developmental Psychology, 47(4), 1054-1064. doi : 10.1037/a0023869.

Killen, M. \& Smetana, J., (2008). Moral Judgment and Moral Neuroscience: Intersections, Definitions, and Issues. Child Development Perspectives, 2(1), 1-6. doi : 10.1111/j.17508606.2008.00033.x

Killen, M., Lynn Mulvey, K., Richardson, C., Jampol, N., \& Woodward, A. (2011). The accidental transgressor: morally-relevant theory of mind. Cognition, 119(2), 197-215. doi:10.1016/j.cognition.2011.01.006

Kohlberg, (1969). Stage and sequence: the cognitive-developmental approach to socialization. In D. A. Goslin, ed., Handbook of Socialization Theory and Research. Chicago: Rand McNally, pp. 347-480 (p. 376).

Lergetporer, P., Angerera, S., Glätzle-Rützlera, D., Suttera, M., (2014). Third-party punishment increases cooperation in children through (misaligned) expectations and conditional cooperation. Proceedings of the National Academy of Sciences of the United States of America. 111(19), 6916-21. doi: 10.1073/pnas.1320451111

Leslie, A. M., Mallon, R., \& DiCorcia, J. a. (2006). Transgressors, victims, and cry babies: is basic moral judgment spared in autism? Social Neuroscience, 1(3-4), 270-83. doi:10.1080/17470910600992197

McAuliffe, K., Jordan, J., \& Warneken, F. (2015). Costly third-party punishment in young children. Cognition. doi:10.1016/j.cognition.2014.08.013

McCrink, K., Bloom, P., \& Santos, L. R. (2010). Children's and adults' judgments of equitable resource distributions. Developmental Science, 13(1), 37-45. doi: 10.1111/j.14677687.2009.00859.x

Meristo, M., \& Surian, L. (2013). Do infants detect indirect reciprocity? Cognition, 129(1), 102113. doi: 10.1016/j.cognition.2013.06.006

Mikhail, J., (2007). Universal moral grammar: theory, evidence and the future. Trends in cognitive sciences, 11(4), pp.143-52. 10.1016/j.tics.2006.12.007 
Nobes, G., Panagiotaki, G., \& Pawson, C. (2009). The influence of negligence, intention, and outcome on children's moral judgments. Journal of Experimental Child Psychology, 104(4), 382-97. doi:10.1016/j.jecp.2009.08.001

Olson, K.R. \& Spelke, E.S., (2008). Foundations of cooperation in young children. Cognition, 108(1), 222-31. doi: 10.1016/j.cognition.

Piaget, J. (1932). The Moral Judgment of the Child. London: Routledge and Kegan Paul.

Premack, D and Premack A.J., (1997). Infants Attribute Value \pm to the Goal-Directed Actions of Self-propelled Objects. Journal of cognitive neuroscience. 9(6):848-56. doi: 10.1162/jocn.1997.9.6.848.

Rand, D. G., Greene, J. D., \& Nowak, M. A. (2012). Spontaneous giving and calculated greed. Nature, 489. doi : 10.1038/nature11467

Rochat, P., Dias M. D. G. , Liping, G., Broesch, T., Passos-Ferreira, C., Winning, A., \& Berg, B., (2009). Fairness in Distributive Justice by 3- and 5-Year-Olds Across Seven Cultures. Journal of Cross-Cultural Psychology, 40(3), 416-442. doi: 10.1177/0022022109332844

Scarf, D., Imuta, K., Colombo, M., \& Hayne, H. (2012). Golden Rule or valence matching? Methodological problems in Hamlin et al. Proceedings of the National Academy of Sciences, 109(22), E1426-E1426. doi:10.1073/pnas.1204123109

Schmidt, M. F. H., \& Sommerville, J. a. (2011). Fairness expectations and altruistic sharing in 15month-old human infants. PloS One, 6(10), e23223. doi:10.1371/journal.pone.0023223

Smetana, J.G., (1981). Preschool Children's Conceptions of Moral and Social Rules. Child Development, 52(4), p.1333-36. doi: 10.2307/1129527

Smetana, J.G. (2006). Social-cognitive domain theory: Consistencies and variations in children's moral and social judgments. In M. Killen \& J.G. Smetana (Eds.), Handbook of moral development (pp. 119-154). Mahwah: Erlbaum Associates.

Steinberg, L., \& Morris, A. S. (2001). Adolescent development. Annual Review of Psychology, 52, 83-110. doi:10.1146/annurev.psych.52.1.83

Theimer, C. E., Killen, M., \& Stangor, C. (2001). Young children's evaluations of exclusion in gender-stereotypic peer contexts. Developmental Psychology, 37(1), 18-27. doi : 10.1037/0012-1649.37.1.18 
Tomasello, M., \& Vaish, A. (2013). Origins of human cooperation and morality. Annual Review of Psychology, 64, 231-55. doi: 10.1146/annurev-psych-113011-143812

Turiel, E. (1998). The development of morality. In W. Damon (gen. ed.), N. Eisenberg (vol. ed.), Handbook of Child Psychology, 5th edn. Vol. III: Social, Emotional, and Personality Development, New York: Wiley, pp. 863-932.

Turiel, E. (2006). Thought, emotions, and social interactional processes in moral development. In M. Killen \& J.G. Smetana (Eds.), Handbook of moral development. (pp. 7-35). Mahwah: Erlbaum Associates.

Turiel, E., \& Nucci, L. (1978). Social interactions and the development of social concepts in preschool children. Child Developlment, 49(2), 400-407.

Van den Bos, W., Westenberg, M., van Dijk, E., \& Crone, E. A. (2010). Development of trust and reciprocity in adolescence. Cognitive Development, 25, 90-102. http://doi.org/10.1016/j.cogdev.2009.07.004

Will, G.-J., Crone, E. A., van den Bos, W., \& Güroğlu, B. (2013). Acting on observed social exclusion: Developmental perspectives on punishment of excluders and compensation of victims. Developmental Psychology, 49(12), 2236-2244. http://doi.org/10.1037/a0032299

Young, L., \& Dungan, J. (2012). Where in the brain is morality? Everywhere and maybe nowhere. Social Neuroscience, 7(1), 1-10. doi:10.1080/17470919.2011.569146

Young, L. L., Koenigs, M., Kruepke, M., \& Newman, J. P. (2012). Psychopathy increases perceived moral permissibility of accidents. Journal of Abnormal Psychology, 121(3), 1-33, doi : 10.1037/a0027489

Yamaguchi, M., Kuhlmeier, V. a, Wynn, K., \& vanMarle, K. (2009). Continuity in social cognition from infancy to childhood. Developmental Science, 12(5), 746-52. doi:10.1111/j.14677687.2008.00813.x 